\title{
A FORMAÇÃO CIENTÍFICA SOBRE SEXUALIDADE NOS CURSOS DE GRADUAÇÃO EM PSICOLOGIA DA REGIÃO DE CURITIBA
}

\author{
Cláudia Vaz', Fernanda Torres²
}

BONATO, Fernanda Rafaela Cabral. A formação científica sobre sexualidade nos cursos de graduação em psicologia da região de Curitiba. 2019. Dissertação (Mestrado em Psicologia) - Setor de Ciências Humanas, Universidade Federal do Paraná, Curitiba, 2019.

A dissertação de Fernanda Bonato teve como objetivo investigar a formação científica a respeito da sexualidade em atividades acadêmicas e nos currículos de cursos de graduação em Psicologia da região de Curitiba, bem como quais os sentidos subjetivos acerca da temática da sexualidade produzidos pelos(as) estudantes de Psicologia, possibilitando levantar algumas indagações e reflexões críticas em relação à formação acadêmica e profissional do(a) psicólogo(a) da região de Curitiba (p. 17). $O$ trabalho fundamentou-se na Epistemologia Qualitativa, na Teoria da Subjetividade e no método construtivo-interpretativo.

A pesquisadora analisou o ementário dos cursos de Psicologia de cinco Instituições de Ensino Superior (IES) coparticipantes, para investigar se e/ou como a sexualidade tem sido abordada nas disciplinas que constituem o currículo do curso de graduação em Psicologia e aplicou um questionário on-line aos estudantes dos dois últimos anos do curso de Psicologia das IES coparticipantes, com o objetivo de analisar o que os(as) estudantes diziam sobre a formação curricular a respeito da sexualidade humana.

A dissertação está estruturada em cinco capítulos. No capítulo I a autora, para compreender o atual processo de formação do(a) psicólogo(a) da região de Curitiba, procurou conhecer como os cursos de Psicologia foram estruturados e regulamentados no cenário nacional, refletindo sobre como a profissão foi constituída, as competências e áreas de atuação do(a) profissional de Psicologia, identificando as alterações que a profissão sofreu desde sua regulamentação e o que está estabelecido nas atuais diretrizes curriculares destinadas aos cursos de graduação em Psicologia no Brasil. O primeiro curso de Psicologia foi instaurado no Brasil, na Pontifícia Universidade Católica do Rio de Janeiro em 1953 com a Lei no 4.119 de 27 de agosto de 1962, que se dispôs sobre os cursos de formação em Psicologia e regulamentou a profissão de psicólogo(a) no território nacional (p. 23).

No capítulo 2 com o título "Sexualidade e psicologia: relações entre estas ciências", a autora pontua que a sexualidade, como fator constitutivo da subjetividade humana, vem sendo estudada profundamente por diversas ciências, influenciada pela história, pela cultura e pelas regras sociais. Então:

[...] pensar a sexualidade sob o viés da Psicologia é necessário, pois a vivência da sexualidade na mesma medida que pode trazer um sentimento de prazer, pode ser fonte de angústia, sofrimento, preconceito, dúvidas e tabus, tanto no que tange a vivência do ato sexual em si, como em relação a identidade e orientação sexual (BONATO, 2019, p. 53).

Seguindo está análise, a autora enfatiza o caráter histórico, social e cultural nos estudos sobre sexualidade. Ainda nesse capítulo a autora aponta estudos que contestam o modo como a sociedade regula os comportamentos, as relações sexuais impondo categorias aos seres humanos com base em concepções que formam a sexualidade

O capítulo 3 apresenta a teoria da subjetividade e a epistemologia qualitativa segundo Fernando González Rey. A autora explica que adotou como base a teoria da subjetividade, a epistemologia qualitativa e o método construtivo-interpretativo desenvolvidos por Fernando González Rey, um autor e teórico da Psicologia Histórico Cultural que analisou os conceitos de sujeito e subjetividade como categorias que a Psicologia deveria debruçar-se para a compreender a realidade humana.

A autora explica que a subjetividade, categoria importante no trabalho, não pode ser considerada estática,

\footnotetext{
Doutora e mestre em Educação pela Universidade Federal da Bahia (UFBA). Psicóloga (CRP 03/I530). Professora da Universidade Salvador (UNIFACS) e da Universidade do Estado da Bahia. E-mail: vaztorres@gmail.com

2 Psicóloga. Graduanda em Pedagogia. Orientadora pedagógica. Aluna do curso de Especialização em Psiconeurologia na UNIFACS. E-mail: fernandavaztorres@gmail.com
} 
é uma produção singular caracterizada por uma experiência vivida no campo individual e social de modo dialético, que se tem acesso na pesquisa a partir da dialogicidade, que proporciona que os sentidos subjetivos sejam reconhecidos por meio da produção da pesquisa.

O capítulo 4 descreve o método construtivo interpretativo, pautado na epistemologia qualitativa, que se caracteriza por ser um processo relacional, em que o(a) pesquisador(a) é um sujeito ativo(a), que evidencia posicionamento como fundamento primordial da pesquisa.

A construção do cenário social da pesquisa que estrutura o caráter dialógico, o interesse e o engajamento com a instituição e com os(as) possíveis participantes da pesquisa foi iniciado com o contato com os(as) coordenadores(as) dos dez cursos de graduação de Psicologia de IES da região de Curitiba. Depois de firmada a parceria com cinco coordenadores(as) das instituições coparticipantes, houve a divulgação da pesquisa e realização das oficinas com 12 estudantes que demonstraram interesse, compareceram aos encontros, sendo seis das IES pública e seis das particulares. Os(as) alunos(as) participantes estudavam em distintas IES da região de Curitiba, sendo II pessoas do gênero feminino e uma do gênero masculino. Quanto aos instrumentos para ter acesso as expressão dos sentidos subjetivos individuais e sociais, foram utilizados instrumentos de pesquisas individuais, como redações, trechos de informação e complemento de frases provenientes das discussões em grupo e instrumentos de pesquisa coletivos que abordavam questões relacionadas à sexualidade, como conversações, dinâmicas grupais e debates sobre filmes, documentários e séries. Acrescenta-se que a pesquisa foi aprovada pelo Comitê de Ética e Pesquisa da Universidade Federal do Paraná.

A autora analisou o ementário, sendo que das cinco IES coparticipantes três disponibilizaram o ementário de maneira integral. Nas outras duas instituições a análise do ementário ocorreu por meio do(a) próprio(a) coordenador(a) do curso de Psicologia, que analisou quais matérias abordavam a temática da sexualidade de maneira direta e indireta.

No capítulo que trata do processo de construção da informação e discussão de dados, a autora constatou que as IES não haviam abordado o tema da sexualidade ao longo da formação acadêmica dos(as) alunos(as), que havia um silenciamento durante a graduação em Psicologia sobre os temas concernentes a sexualidade, o que gerava um sentimento de insegurança e despreparo para futura atuação profissional. Com base nos relatos, a autora criou dois indicadores referentes a existência da lacuna e um silenciamento das IES diante de temas relacionados à sexualidade (indicador I) e o de que ao não se falar sobre estes temas, concepções ultrapassadas da sexualidade são mantidas entre os(as) futuros(as) profissionais gerando uma desatualização das informações científicas sobre sexualidade (indicador 2) (BONATO, 2019). Constatou-se, a partir de outros indicadores que há um despreparo e desconhecimento sobre como a sexualidade foi vivenciada, compreendida e normatizada no decurso da humanidade, assim como é feita a abordagem por distintas áreas de saber. Os relatos evidenciaram a necessidade de formação profissional sobre a sexualidade para profissionais de Psicologia.

Mais indicadores foram criados para abordar a temática com os estudantes: 6. A transmissão de informações sobre sexualidade é ínfima na graduação em Psicologia; 7. A Psicologia reproduz, num microcosmos, o que acontece em relação ao restante da sociedade no que tange a negação da sexualidade 8 . Desconhecimento de conceitos chaves a sexualidade; 9. A Psicologia pode ser prejudicada diante desta lacuna na formação profissional; 10. Dificuldade em abordar a sexualidade nos diferentes espaços que formam as IES; I I. O conhecimento dos acadêmicos sobre sexualidade é construído em um espaço alheio ao ambiente de ensino superior; 12. A teoria psicanalítica é a que mais aborda a temática da sexualidade na formação acadêmica de Psicologia.

A pesquisadora constatou que conceitos chaves da sexualidade são desconhecidos por grande parte dos(as) estudantes e que não estão de acordo com as Diretrizes Curriculares Nacionais para os cursos de graduação em Psicologia - Resolução $\mathrm{n}^{\circ} 5$ de 05 de março de $201 \mathrm{l}$ o que tem relação direta com a lacuna e o silenciamento das IES sobre a temática. Dos cinco cursos de Psicologia das IES coparticipantes somente dois têm uma disciplina obrigatória sobre sexualidade, porém estas não abordam todas as temáticas da sexualidade.

A autora finaliza indicando que os cursos de graduação em Psicologia deveriam abordar a sexualidade tanto de um viés sociológico, como também da saúde, pois desta forma temas como gênero, direitos humanos, transexualidade, construção histórica da sexualidade, violência, saúde sexual, prazer, fisiologia, ciclos de resposta sexual, disfunções sexuais, entre outros, seriam abordados ao longo da graduação. A dissertação evidencia a necessidade da formação científica sobre sexualidade na graduação em Psicologia. 